\title{
Roles of gene transcription and PKA subtype activation in maturation of murine oocytes
}

\author{
K. F. Rodriguez, R. M. Petters, A. E. Crosier and C. E. Farin* \\ Department of Animal Science, North Carolina State University, 231B Polk Hall, \\ Raleigh, NC 27695-7621, USA
}

The aims of this study were to examine the role of transcription and the coincident involvement of type I and type II protein kinase $\mathrm{A}$ (PKA) in the resumption of meiosis in murine cumulus-oocyte complexes (COCs) using the transcriptional inhibitors 5,6-dichloro-1- $\beta$-D-ribofuranosylbenzimidazole (DRB) and $\alpha$-amanitin. The first series of experiments was designed to: (i) characterize the role of transcription in gonadotrophin-mediated and spontaneous maturation of murine oocytes; (ii) examine the roles of specific gonadotrophins (FSH versus hCG) and cumulus cells in transcriptionally mediated oocyte maturation; and (iii) determine the reversibility of the transcriptional arrest of meiosis. In the presence of $\mathrm{FSH}$, transcriptional inhibitors arrested germinal vesicle breakdown (GVBD) (DRB: $2 \pm 2 \%$ and control: $76 \pm 2 \% ; \alpha$-amanitin: $4 \pm 4 \%$ and control: $70 \pm 4 \%$ ). Furthermore, cumulus cells were required for transcriptional inhibitors to arrest GVBD (DRB with cumulus cells: $0 \pm 15 \%$; DRB without cumulus cells: $94 \pm 13 \%$; $\alpha$-amanitin with cumulus cells: $15 \pm 2 \%$; $\alpha$-amanitin without cumulus cells: $99 \pm 2 \%$ ). Thus, in mice, FSH-mediated GVBD uses a transcriptional mechanism, which probably occurs within the cumulus cell compartment. In a second series of experiments, the role of transcription in mediating the resumption of meiosis after activation of either type I or type II PKA was examined. Activation of type I PKA in murine COCs resulted in an arrest of GVBD that was independent of a transcriptional event (with DRB: $7 \pm 9 \%$ GVBD; without DRB: $11 \pm 9 \%$ GVBD). In contrast, activation of type II PKA resulted in a resumption of meiosis, which required the occurrence of gene transcription (with DRB: $12 \pm 9 \%$ GVBD; without DRB: $80 \pm 9 \%$ GVBD). As FSH binding to cumulus cells activates the PKA second messenger system, our results indicate that, in cultured murine COCs, FSH binding to cumulus cells results in the activation of type II PKA, which, in turn, mediates a downstream transcriptional event required for the initiation of GVBD.

\section{Introduction}

The resumption of meiosis in oocytes is characterized by chromosome condensation, germinal vesicle breakdown (GVBD) and progression to meiosis I. In vivo, this occurs in response to the preovulatory surge of gonadotrophins (Tsafriri et al., 1976). In vitro, maturation occurs spontaneously in the absence of gonadotrophins when the oocyte is removed from the intrafollicular environment (Pincus and Enzmann, 1935). As maturation can be prevented by increased cAMP in isolated cumulus-oocyte complexes (COCs) and denuded oocytes (Dekel et al., 1981; Schultz et al., 1983a; Downs and Eppig, 1984; Eppig, 1989), spontaneous maturation is thought to result from a decrease in intra-oocyte cAMP content.

Specific inhibitors of RNA polymerase II, such as $\alpha$ amanitin or 5,6-dichloro-1- $\beta$-D-ribofuranosyl-benzimidazole (DRB), have been used to demonstrate that gonadotrophinmediated resumption of meiosis in pigs (Meinecke and

*Correspondence

Email: Char_Farin@ncsu.edu
Meinecke-Tillmann, 1993), sheep (Osborn and Moor, 1983) and cows (Kastrop et al., 1991; Farin and Yang, 1994) requires an initial transcriptional event that occurs in the cumulus cell compartment of COCs. In bovine COCs, transcriptional events initiated by FSH did not occur when COCs resumed meiosis spontaneously or in the presence of hCG (Wolf and Farin, 1996). In mice, it has been suggested that GVBD may not be mediated by a transcriptional event (Crozet and Szollosi, 1980). However, in hypoxanthinearrested murine COCs, $\alpha$-amanitin blocked the induction of meiosis by $\mathrm{FSH}$, indicating a possible role for transcription in this model system (Downs, 1995; Downs et al., 1996).

Signal transduction by FSH occurs after binding to its receptor, which results in stimulation of adenylyl cyclase and activation of CAMP-dependent protein kinase A (PKA) (Hunzicker-Dunn and Jungmann, 1978). PKA is a tetrameric molecule consisting of a regulatory subunit dimer. Each regulatory subunit is bound to one inactive catalytic subunit. There are two isozymes of PKA, designated as type I and type II on the basis of order of elution of their regulatory subunits (RI and RII, respectively) from anion exchange resins (Corbin et al., 1975). There are two CAMP binding sites on each of these regulatory subunits. Within each regulatory subunit, 
the two CAMP binding sites differ on the basis of their rate of exchange and affinity for $\left[{ }^{3} \mathrm{H}\right] \mathrm{CAMP}$ (Potter and Taylor, 1980; Doskeland and Ogreid, 1984). By using combinations of cAMP analogues that bind selectively to each site on the regulatory subunits, it is possible to activate either type I or type II PKA differentially (Ogreid et al., 1989). Differential activation of PKA isozymes has opposing effects on maturation of murine oocytes. Oocytes were arrested at the germinal vesicle stage after activation of type I PKA, whereas activation of type II PKA stimulated GVBD in oocytes arrested by isobutyl methylxanthine (IBMX) (Downs and Hunzicker-Dunn, 1995).

The role of de novo gene transcription after specific gonadotrophin stimulation and PKA activation has not been characterized for maturation of murine oocytes. The aims of the present study were to examine the role of transcription and the coincident involvement of type I and type II PKA in the resumption of meiosis in murine COCs.

\section{Materials and Methods}

\section{Reagents and media}

5,6-Dicholoro-1- $\beta$-D-ribofuranosyl-benzimidazole (DRB, Lot $027 \mathrm{H} 4086)$ and the cAMP analogues, $N^{6}$-monobutyrylcyclic adenosine monophosphate $\left(N^{6}\right)$, aminohexyl-aminocyclic adenosine monophosphate (AHA) and 8-bromo-cyclic adenosine monophosphate $(8-\mathrm{Br})$ were purchased from Sigma Chemical Co. (St Louis, MO). $\alpha$-Amanitin was purchased from Boehringer Mannheim (Indianapolis, IN). hCG (75 iu ${ }^{-1}$; Sigma Chemical Co.) and FSH $\left(0.5 \mu \mathrm{g} \mathrm{ml}^{-1}\right.$; USDA oFSH-18) were used as media supplements. Unless otherwise noted, chemicals for preparation of media were from Sigma Chemical Co. and were of tissue culture grade. The eCG used for superovulation was also obtained from Sigma Chemical Co.

Waymouth medium supplemented with $5 \%$ fetal bovine serum, $0.23 \mathrm{mmol}$ pyruvate $\mathrm{I}^{-1}, 7 \mathrm{mmol}$ taurine $\mathrm{I}^{-1}$, $50 \mathrm{mg}$ streptomycin sulphate $\mathrm{I}^{-1}$ and $75 \mathrm{mg}$ penicillin $\mathrm{G} \mathrm{I}^{-1}$ was used for oocyte cultures. $\alpha$-Amanitin was dissolved in culture medium $\left(10 \mu \mathrm{g} \mathrm{ml}^{-1}\right)$ immediately before use. A stock solution of DRB (20 $\mathrm{mg} \mathrm{m}^{-1}$ ) was prepared in dimethyl sulphoxide (DMSO) and added to the culture medium at $120 \mu \mathrm{mol} \mathrm{I}^{-1}$. This dose was chosen after evaluation of doses ranging from 30 to $150 \mu \mathrm{mol}$ DRB $\left.\right|^{-1}$ to maintain murine COCs at the germinal vesicle stage for a $3 \mathrm{~h}$ culture period (data not shown).

Differential activation of PKA subunits was performed by supplementing media with different combinations of CAMP analogues: $N^{6}$ and AHA were used for activation of type I PKA, and $8-\mathrm{Br}$ and $N^{6}$ were used for activation of type II PKA (Downs and Hunzicker-Dunn, 1995). The analogues were dissolved in DMSO and used immediately. An equimolar concentration of each analogue was used to achieve the final concentration indicated for each specific experimental group.

\section{Role of transcription in gonadotrophin-mediated resumption of meiosis}

Oocyte recovery and culture conditions. Prepubertal
Swiss Albino mice (aged 20-23 days; Taconic, Germantown, NY) were maintained on a $12 \mathrm{~h}$ light:12 h dark cycle with access to food and water available ad libitum. A minimum of six mice was used in each replicate for all experiments. Mice were given an i.p. injection of 5 iu eCG and were killed by cervical dislocation $48 \mathrm{~h}$ later. Ovaries were dissected into culture medium, extracted from the bursa, cleaned of adhering fat, bisected and distributed to dishes containing appropriate treatment media. Each demi-ovary was bisected and the halves were distributed such that each mouse contributed ovarian tissue to all four treatment groups in each experiment. Antral follicles on each quarterovary were punctured with a sterile needle and COCs were collected. The COCs were washed once in fresh treatment medium and cultured in multi-well dishes containing $0.5 \mathrm{ml}$ treatment medium. All cultures were conducted at $37^{\circ} \mathrm{C}$ in an atmosphere of $5 \% \mathrm{CO}_{2}$ in air with $100 \%$ humidity. At the termination of culture, oocytes were denuded of their cumulus cells by manual pipetting and assessed visually for the resumption of meiosis at a magnification of $\times 60$ using a stereomicroscope. Oocytes without an intact germinal vesicle were classified as having undergone GVBD. Oocytes with a dark or fragmented ooplasm or dark cumulus cells were classified as degenerated. All procedures involving animals were carried out in accordance with $\mathrm{NIH}$ guidelines for the care and use of laboratory animals under the approval of the North Carolina State University Institutional Animal Care and Use Committee.

Effect of gonadotrophins on inhibition of meiotic maturation by $D R B$ or $\alpha$-amanitin. Two experiments were conducted. For both Expts $1 \mathrm{a}$ and $1 \mathrm{~b}$, COCs were distributed to one of four treatments in a $2 \times 2$ factorial arrangement. In Expt 1a, the main factors were transcriptional inhibitor (DRB versus vehicle control) and gonadotrophin treatment (FSH plus hCG versus medium control). In Expt 1b, the main factors were transcriptional inhibitor ( $\alpha$-amanitin versus medium control) and gonadotrophin treatment (FSH plus hCG versus medium control). Oocytes were assessed for GVBD after $3 \mathrm{~h}$ culture. Each experiment was replicated four times and included an average of $145 \pm 28$ COCs (Expt $1 \mathrm{a})$ and $143 \pm 27$ COCs (Expt 1b) per replicate.

Effect of supplementation with either hCG or FSH on inhibition of meiotic maturation by DRB or $\alpha$-amanitin. Two experiments were conducted. Each experiment included treatments in a $2 \times 2$ factorial arrangement with the major factors being presence or absence of specific gonadotrophins (FSH, hCG). In Expt 2a, all media were supplemented with $120 \mu \mathrm{mol}$ DRB I-1. In Expt 2b, all media were supplemented with $10 \mu \mathrm{g} \alpha$-amanitin $\mathrm{ml}^{-1}$. Oocytes were denuded and assessed for GVBD after $3 \mathrm{~h}$ culture. Each experiment was replicated four times and included an average of $129 \pm 18$ COCs (Expt 2a) and $136 \pm 30$ COCs (Expt 2b) per replicate.

Effect of removal of cumulus cells on the inhibition of oocyte maturation by DRB or $\alpha$-amanitin. For these two 
experiments, all media were supplemented with $0.5 \mu \mathrm{g} \mathrm{FSH}$ $\mathrm{ml}^{-1}$. When appropriate, COCs were denuded by manual pipetting in treatment medium before initiation of culture. In Expt 3a, treatment groups were in a $2 \times 2$ factorial arrangement with the major factors being presence or absence of transcriptional inhibitor (DRB) and presence or absence of cumulus cells surrounding the oocyte. In Expt $3 \mathrm{~b}$, the major treatment factors were transcriptional inhibitor ( $\alpha$-amanitin) and the presence or absence of cumulus cells. For both experiments the cultures continued for $3 \mathrm{~h}$. After culture, all COCs were denuded by manual pipetting and assessed for GVBD. The experiments were replicated four times and included an average of $127 \pm 25$ COCs (Expt 3a) and $135 \pm 24$ COCs (Expt 3b) per replicate, respectively.

Reversibility of $D R B$ - and $\alpha$-amanitin-mediated arrest of $G V B D$. All media for Expts $4 \mathrm{a}$ and $4 \mathrm{~b}$ were supplemented with $0.5 \mu \mathrm{g} \mathrm{FSH} \mathrm{ml}{ }^{-1}$. In Expt 4a, COCs were distributed to one of five treatment groups: without DRB, $3 \mathrm{~h}$ (culture for $3 \mathrm{~h}$ in control medium); with DRB, $3 \mathrm{~h}$ (culture for $3 \mathrm{~h}$ in medium supplemented with DRB); with DRB reverse (culture for $3 \mathrm{~h}$ in medium supplemented with DRB followed by transfer to inhibitor-free medium and culture for an additional $3 \mathrm{~h}$ ); without DRB reverse (culture for $3 \mathrm{~h}$ in control medium, transfer to fresh control medium, culture for an additional $3 \mathrm{~h}$ ); with DRB, $6 \mathrm{~h}$ (culture for $3 \mathrm{~h}$ in DRBsupplemented medium, transfer to DRB-supplemented medium, culture for an additional $3 \mathrm{~h}$ ). This final group was considered as an experimental control and was included to demonstrate that if the oocytes were cultured continuously for $6 \mathrm{~h}$ in the presence of the inhibitor, the arrest of maturation would be maintained. At the termination of treatment, COCs from each group were denuded and assessed for the occurrence of GVBD.

In Expt 4b, the treatment groups were the same as in Expt $4 a$ with the exception that $\alpha$-amanitin was used as the transcriptional inhibitor in place of DRB. The experiments were each replicated four times and included an average of $164 \pm 50$ COCs (Expt 4a) and $82 \pm 13$ COCs (Expt 4b) per replicate, respectively.

\section{Role of PKA isozymes in facilitating resumption of meiosis}

Oocyte recovery and culture conditions. Prepubertal Swiss albino mice (age 20-23 days) were housed and superovulated as described previously. For all experiments, a minimum of 12 mice was used in each replicate. Ovaries were collected as described previously and then bisected. Each demi-ovary was distributed randomly to dishes containing treatment media such that no mouse would contribute more than one demi-ovary to the same treatment. Cultures were performed in the absence of gonadotrophin stimulation unless specifically noted. COCs were cultured for 3 or $4 \mathrm{~h}$, after which the COCs were stripped by manual pipetting and assessed for GVBD.
Effect of differential activation of type I or type II PKA on resumption of meiosis. The analogues used for activation of type I PKA were $N^{6}$ and AHA, whereas the analogues used for the activation of type II PKA were $N^{6}$ and $8-B r$ (Downs and Hunzicker-Dunn, 1995). In the first two replicates of this experiment, the analogues used for activation of either type I or type II PKA were used at concentrations of 0,50 or $100 \mu \mathrm{mol} \mathrm{I}^{-1}$. In the second two replicates, two additional concentrations (5 and $10 \mu \mathrm{mol} \mathrm{I}^{-1}$ ) were also included. Cultures were continued for $3 \mathrm{~h}$, after which time the oocytes were stripped from their cumulus cells and assessed for GVBD. The experiment was replicated four times and included an average of $212 \pm 25$ COCs per replicate.

Role of transcription in regulating meiosis after differential activation of type I or type II PKA. On the basis of the previous analysis, two effective concentrations for activation of type I or type II PKA were chosen for further study. The COCs were distributed randomly to one of 12 treatment groups and cultured for $4 \mathrm{~h}$. The 12 treatment groups were arranged in three subgroups: control groups: $n=4$ groups that included all combinations of treatments with and without FSH and with and without DRB; type I activation groups: $n=4$ groups that included 10 or $50 \mu \mathrm{mol} \mathrm{I}^{-1}$ type I CAMP analogues in the presence or absence of DRB; and type II activation groups: $n=4$ groups that included 5 or $10 \mu \mathrm{mol} \mathrm{I-1}$ type II cAMP analogues in the presence or absence of DRB. After termination of culture, COCs were stripped of their cumulus cells by manual pipetting and assessed for GVBD. The experiment was replicated four times with an average of $201 \pm 94$ COCs per replicate.

\section{Statistical analysis}

Data on the percentage of oocytes undergoing GVBD were analysed both as raw data and as arcsine-transformed data by ANOVA using general linear model procedures. When a significant $F$ statistic was found, the means were separated using Duncan's new multiple-range test (SAS, 1988). All data are reported as least squares means \pm SE and the significant differences were based on the analysis of the transformed data. The number of oocytes per replicate is expressed as mean \pm SD. $P<0.05$ was considered significant.

\section{Results}

\section{Role of transcription in gonadotrophin-mediated resumption of meiosis}

Effect of gonadotrophins on inhibition of meiotic maturation by DRB or $\alpha$-amanitin. Meiotic maturation occurring in the presence of gonadotrophins was sensitive to transcriptional inhibition by either DRB or $\alpha$-amanitin (Fig. 1a,b). In contrast, neither inhibitor was effective at arresting GVBD when COCs were cultured in the absence of gonadotrophins. On the basis of these observations, nascent gene transcription was required for gonadotrophin-mediated resump- 
tion of meiosis. In contrast, resumption of meiosis in the absence of gonadotrophins (spontaneous maturation) did not require a transcriptional event. A subsequent experiment was conducted to determine whether transcriptional activation occurred in response to a specific gonadotrophin (hCG or FSH).

Effect of hCG or FSH on inhibition of meiotic maturation by $D R B$ or $\alpha$-amanitin. GVBD initiated in the presence of FSH and hCG or FSH alone was effectively blocked by treatment with either DRB or $\alpha$-amanitin (Fig. 1c,d). GVBD initiated in the presence of hCG alone or in the complete absence of gonadotrophins was not sensitive to transcriptional inhibition. Thus, FSH-mediated resumption of meiosis occurred through a transcriptional pathway that was not used during either spontaneous maturation or hCG-mediated resumption of meiosis.

Effect of removal of cumulus cells on the inhibition of oocyte maturation by $D R B$ or $\alpha$-amanitin. In the presence of cumulus cells, both DRB and $\alpha$-amanitin effectively inhibited FSH-mediated GVBD (Fig. 1e,f). However, when cumulus cells were removed, neither transcriptional inhibitor was effective at preventing GVBD. These data indicate that the transcriptional event initiated during $\mathrm{FSH}$-mediated GVBD probably occurred in the cumulus cell compartment.

Reversibility of $D R B$ - and $\alpha$-amanitin-mediated arrest of GVBD. As $\alpha$-amanitin has been associated with oocyte and embryo degeneration (Kidder et al., 1985; Hunter and Moor, 1987), the capacity of murine COCs to continue maturation after culture in the presence of either transcriptional inhibitor was examined. Transcriptional inhibition of FSH-mediated GVBD was reversible and was not associated with oocyte degeneration (Fig. 1g,h). Ninety-eight per cent of COCs cultured for $3 \mathrm{~h}$ in the presence of DRB and $81 \%$ of COCs cultured in the presence of $\alpha$-amanitin remained at the germinal vesicle stage (with DRB, $3 \mathrm{~h}$ and with $\alpha$-amanitin, $3 \mathrm{~h}$, respectively). After $6 \mathrm{~h}$ of culture in the presence of DRB, $89 \%$ of COCs remained at the germinal vesicle stage and after $6 \mathrm{~h}$ of culture in the presence of $\alpha$-amanitin $85 \%$ remained at the germinal vesicle stage (with DRB, $6 \mathrm{~h}$ and with $\alpha$-amanitin, $6 \mathrm{~h}$, respectively). When COCs were exposed to DRB or $\alpha$-amanitin and then transferred to inhibitor-free medium and cultured for an additional $3 \mathrm{~h}$, approximately $92 \%$ of COCs (with DRB reverse group) and $66 \%$ (with $\alpha$-amanitin reverse group) underwent GVBD. Compared with treatments with DRB, differences in reversibility associated with $\alpha$-amanitin were not due to an increased incidence of oocyte degeneration, as $<1.5 \%$ (28/2009) of oocytes were degenerate after treatment with $\alpha$-amanitin.

\section{Role of PKA isoenzymes in facilitating resumption of meiosis}

Effect of activation of type I or type II PKA on meiotic resumption: dose-response analysis. Increasing concentrations of type I PKA activators resulted in a dose-dependent decrease in the incidence of GVBD in cultured murine COCs (Fig. 2). As activation of type II PKA was reported to initiate resumption of meiosis in dbcAMP-arrested COCs (Downs and Hunzicker-Dunn, 1995), the most effective concentrations for activation of type II PKA were defined as the lowest concentrations used that did not interfere with oocyte maturation. These concentrations were 5 and $10 \mu \mathrm{mol} \mathrm{I}^{-1}(84.1 \pm 14.3$ and $88.5 \pm 14.3 \%$ GVBD, respectively; Fig. 2).

Role of transcription in regulating meiosis after differential activation of type I or type II PKA. In the absence of $\mathrm{FSH}$, treatment of murine COCs with type I PKA activators at 10 or $50 \mu \mathrm{mol} \mathrm{I}^{-1}$ significantly inhibited the occurrence of GVBD $(P<0.001)$. There was no effect of treatment with DRB on the percentage of oocytes remaining in germinal vesicle arrest after activation of type I PKA. These observations indicate that inhibition of GVBD by activation of type I PKA may not require a transcriptional event. In contrast, activation of type II PKA resulted in resumption of meiosis requiring a transcriptional event. GVBD was inhibited when DRB was added to media in the presence of activators of type II PKA (Fig. 3). In addition, this degree of inhibition was not different from that found when DRB was used in the presence of FSH $(20.7 \pm 8.4$ and $12.5 \pm 8.4 \%$ GVBD, respectively).

\section{Discussion}

The data from the present study demonstrate that, in cultured murine COCs, FSH-mediated GVBD requires gene transcription. The use of two inhibitors, each of which prevents transcription by different mechanisms, led to similar conclusions. DRB, an analogue of the nucleoside adenosine, acts by preventing the formation of a stable transcription initiation complex (Zandomeni et al., 1983). In contrast, $\alpha$-amanitin acts by inhibiting nucleoplasmic RNA polymerase II specifically (Zubay, 1983). Treatment with either inhibitor did not induce oocyte degeneration during the short-term cultures used throughout these experiments, as only 85 of 4282 oocytes (2\%) were classified as degenerate after culture. In addition, COCs were not required to be maintained in a hypoxanthine-induced meiotic arrest (Downs, 1995; Downs et al., 1996) for either transcriptional inhibitor to prevent gonadotrophin-mediated GVBD.

When gonadotrophins were included in the culture medium, GVBD was initially inhibited in murine (Eppig et al., 1983; Schultz et al., 1983b) and bovine (Farin and Yang, 1994) COCs. This transient inhibition was followed by an acceleration in the rate of GVBD compared with that observed during spontaneous maturation (Downs, 1990b; Farin and Yang, 1994). It has been suggested that the initial inhibitory phase results from an increase in cAMP occurring in response to hormone binding (Eppig and Downs, 1988; Downs, 1990a).

In bovine, pig and ovine COCs, the transcriptional event required for gonadotrophin-induced GVBD occurs within 

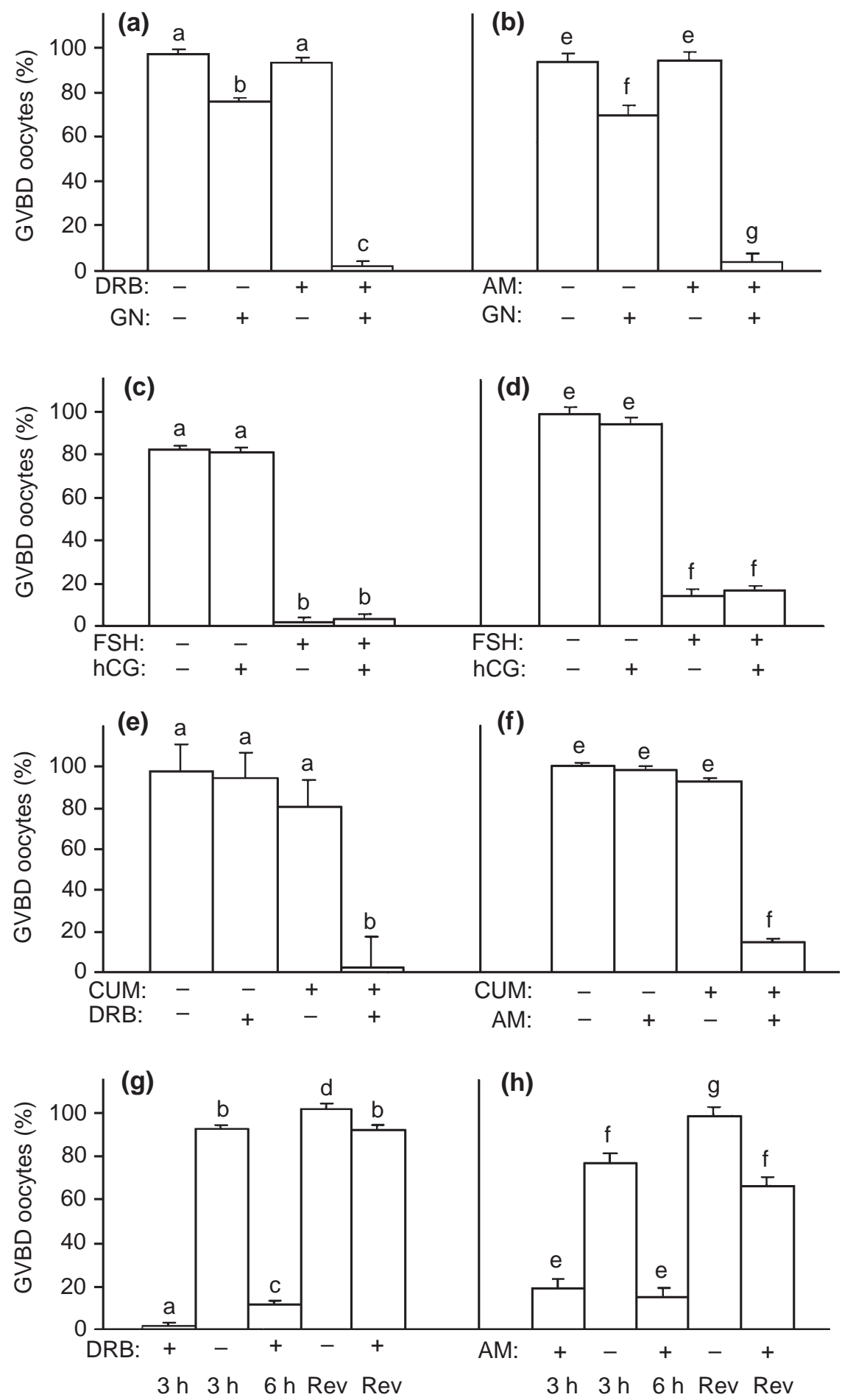

Fig. 1. Characterization of gonadotrophin-mediated germinal vesicle breakdown (GVBD) in murine cumulus-oocyte complexes. (a,b) Effect of gonadotrophins on inhibition of meiotic maturation by 5,6-dichloro-1- $\beta$-D-ribofuranosyl-benzimidazole (DRB) or $\alpha$-amanitin (AM) (GN: FSH plus hCG). (c,d) Effect of hCG or FSH on inhibition of meiotic maturation by DRB

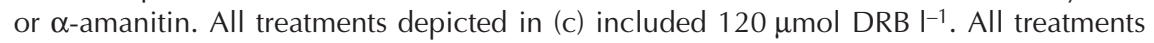
depicted in (d) included $10 \mu \mathrm{g} \alpha$-amanitin $\mathrm{ml}^{-1}$. (e,f) Effect of removal of cumulus cells on inhibition of oocyte maturation by DRB or $\alpha$-amanitin (CUM: cumulus cells; all treatment

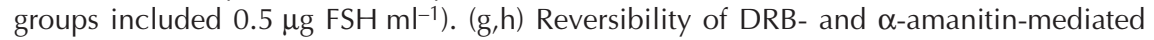
arrest of GVBD (all treatments included $0.5 \mu \mathrm{g} F S H \mathrm{ml}^{-1}$ ). Rev: reverse. ${ }^{\mathrm{a}-\mathrm{d}} \mathrm{P}<0.001$ and e-g $P<0.001$ within each panel. 

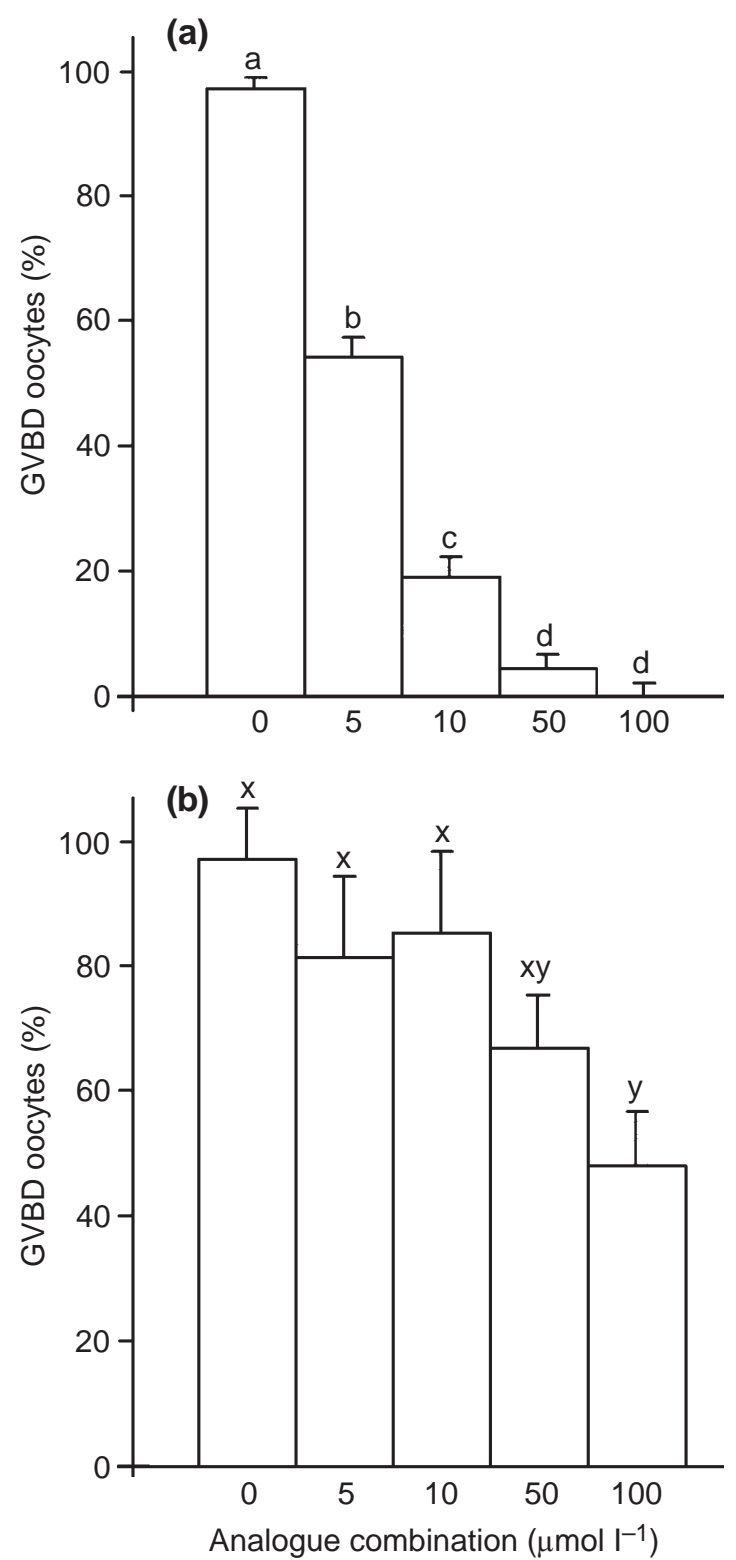

Fig. 2. Effect of activation of (a) type I or (b) type II protein kinase A (PKA) with various concentrations of CAMP analogues on the incidence of germinal vesicle breakdown (GVBD) in murine cumulus-oocyte complexes. Cultures were continued for $3 \mathrm{~h}$ in the presence of either type I activators ( $N^{6}$-monobutyryl-cAMP and 8-aminohexylamino-cAMP) or type II PKA activators ( $N^{6}$-monobutyryl-cAMP and 8-bromo-cAMP) in the absence of gonadotrophin supplementation. ${ }^{a-d} P<0.001$ and $x y P<0.001$ within each panel.

$1 \mathrm{~h}$ of the initiation of culture (Osborn and Moor, 1983; Kastrop et al., 1991; Meinecke and Meinecke-Tillmann, 1993). As the kinetics of maturation in murine oocytes are rapid (Schultz et al., 1983a; Downs et al., 1988), it is likely that this transcriptional event occurs within minutes of the initiation of culture. In cattle and sheep, gonadotrophinmediated maturation required the presence of cumulus cells (Osborn and Moor, 1983; Hunter and Moor, 1987;
Fagbohun and Downs, 1991). In the present study, removal of cumulus cells rendered both DRB and $\alpha$-amanitin ineffective in blocking murine GVBD. These data are consistent with a model in which FSH induces GVBD by a transcriptional event that occurs in the cumulus cells.

It is unlikely that the lack of effectiveness of the transcriptional inhibitors in blocking GVBD in denuded COC resulted from decreased access of the inhibitor to the oocyte. Treatment of bovine COCs with DRB resulted in $>94 \%$ reduction in $\left[{ }^{3} \mathrm{H}\right]$ uridine incorporation into COC mRNA, regardless of the presence or absence of gonadotrophins in the culture medium (Farin and Yang, 1994). In addition, injection of $\alpha$-amanitin directly into denuded pig oocytes was ineffective in blocking GVBD (Meinecke and Meinecke-Tillmann, 1993).

Neither DRB nor $\alpha$-amanitin was effective at preventing spontaneous maturation or hCG-mediated maturation of COCs. In contrast, in the presence of $\mathrm{FSH}$, both transcriptional inhibitors were effective at preventing meiotic resumption. These observations are consistent with those for bovine COCs (Wolf and Farin, 1996) and indicate that GVBD initiated in the presence of FSH involves a transcriptional step that is not required when GVBD occurs spontaneously or under hCG stimulation. It should be noted that COCs from these eCG-stimulated follicles may have few, if any, receptors for LH (Peng et al., 1991; Eppig et al., 1997, 1998). Therefore, these COCs may have been unresponsive to hCG treatment and, as a result, they may have undergone spontaneous GVBD even in the presence of hCG.

On the basis of the data from both the present study and previous studies, a general consensus can be reached regarding the mechanisms of mammalian oocyte maturation for in vitro-cultured COCs. Oocytes undergo either spontaneous or gonadotrophin-mediated maturation. Spontaneous maturation occurs as a result of a decrease in intra-oocyte CAMP content after removal of the oocyte or COC from an inhibitory intrafollicular environment. This would be consistent with the essentially linear kinetics observed for spontaneously maturing murine (Downs and Eppig, 1984) and bovine (Farin and Yang, 1994) COCs. In contrast, gonadotrophin-mediated maturation probably occurs through a mechanism involving $\mathrm{FSH}$ binding to cumulus cells, initiating an increase in intracellular cAMP and activation of type I and type II PKAs. Activation of type I PKA results in a temporary inhibition of oocyte maturation by an intracellular mechanism not involving transcription. Simultaneously, activation of type II PKA would initiate a new gene transcription event that subsequently leads to the resumption of meiosis. This hypothesized mechanism would be consistent with the observations in the present study and with the observations of Downs and Eppig (1984) and Farin and Yang (1994) that culture of COCs in the presence of gonadotrophins first inhibited and then accelerated the rate of GVBD in mice and cattle, respectively. On the basis of the data in the present study, it becomes apparent why oocytes did not revert to spontaneous maturation 


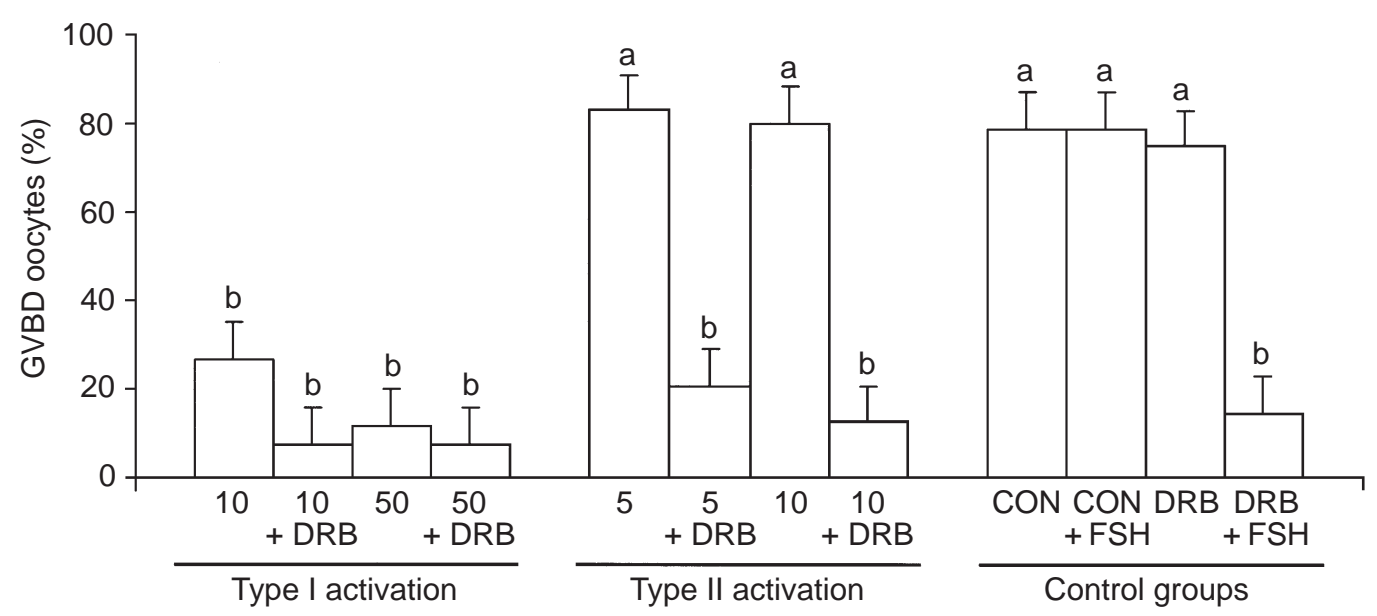

Fig. 3. Role of transcription in germinal vesicle breakdown (GVBD) after activation of type I or type II protein kinase A (PKA). Mouse cumulus-oocyte complexes (COCs) were cultured for $3 \mathrm{~h}$ in the presence of

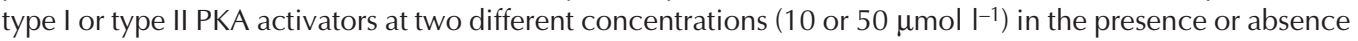
of 5,6-dichloro-1- $\beta$-D-ribofuranosyl-benzimidazole (DRB). CON: COCs cultured in the presence or absence of FSH without DRB supplementation; DRB: COCs cultured in the presence of DRB and in the presence or absence of $\mathrm{FSH} .{ }^{\mathrm{ab}}$ Comparisons are made across all treatment groups $(P<0.001)$.

when arrested at the germinal vesicle stage by transcriptional inhibitors in the presence of FSH. In this case, it is likely that FSH-induced increases in CAMP continued to stimulate type I PKA, which then maintained oocytes in germinal vesicle arrest. However, the simultaneous activation of transcription that is mediated by stimulation of type II PKA and is required for GVBD was blocked by the actions of DRB or $\alpha$-amanitin.

On the basis of this model, it would follow that neither transcriptional nor translational inhibitors would be effective in the absence of an FSH stimulus in any species. This is consistent with reports for mice (Downs, 1990b), rats (Ekholm and Magnusson, 1979), pigs (Fulka et al., 1986; Meinecke and Meinecke-Tillmann, 1993) and cows (Farin and Yang, 1994). Conversely, in the presence of an FSH stimulus it would be anticipated that both transcriptional and translational inhibitors would interrupt GVBD. This has been clearly established in cows and pigs (Fulka et al., 1986; Hunter and Moor, 1987; Kastrop et al., 1991; Meinecke and Meinecke-Tillmann, 1993; Farin and Yang, 1994). Furthermore, murine COCs that were meiotically arrested with hypoxanthine and then cultured in the presence of $\mathrm{FSH}$ were also inhibited from undergoing GVBD by treatment with cyclohexamide (Downs et al., 1996) or $\alpha$-amanitin (Downs, 1995; Downs et al., 1996). The data from the present study demonstrate that, in mice, transcriptional inhibition by either DRB or $\alpha$-amanitin occurred only in the presence of FSH, could be mimicked by activation of type II PKA and did not require previous hypoxanthine-induced meiotic arrest. Together, these observations strongly support the conclusion that transcriptional and translational regulation of GVBD in both murine and livestock COCs is remarkably similar, particularly when assessed under analogous culture conditions.
In conclusion, the mechanisms for FSH-mediated GVBD in cultured murine COCs are similar to those described for in vitro-matured COCs of other species, including cattle. Thus, in cultured murine COCs, FSH binding to cumulus cells results in the activation of type II PKA, which, in turn, mediates a transcriptional event required for the initiation of GVBD.

\section{References}

Corbin JD, Keely SL and Park CR (1975) The distribution and dissociation of cyclic adenosine $3^{\prime}: 5^{\prime}$ monophosphate-dependent protein kinases in adipose, cardiac and other tissues Journal of Biological Chemistry 250 $218-225$

Crozet N and Szollosi D (1980) Effect of actinomyocin D and alphaamanitin on the nuclear ultrastructure of mouse oocytes Biology of the Cell $1980163-170$

Dekel N, Lawrence TS, Gilula NB and Beers WH (1981) Modulation of cellto-cell communication in the cumulus-oocyte complex and the regulation of oocyte maturation by LH Developmental Biology 86 356-362

Doskeland SO and Ogreid D (1984) Characterization of the interchain and intrachain interactions between the binding sites of the free regulatory moiety of protein kinase I Journal of Biological Chemistry 259 2291-2301

Downs S (1990a) The maintenance of meiotic arrest in mammalian oocytes. In Fertilization in Mammals pp 5-16 Eds BD Bavister, J Cummins and ER Roldan. Serono Symposia, Massachusetts

Downs SM (1990b) Protein synthesis inhibitors prevent both spontaneous and hormone-dependent maturation of isolated mouse oocytes Molecular Reproduction and Development 27 235-243

Downs SM (1995) Control of the resumption of meiotic maturation in mammalian oocytes In Gametes - The Oocyte pp 150-192 Eds JG Grudzinskas and JL Yovich. Cambridge University Press, Cambridge

Downs SM and Eppig JJ (1984) Cyclic adenosine monophosphate and ovarian follicular fluid act synergistically to inhibit mouse oocyte maturation Endocrinology 114 418-427

Downs SM and Hunzicker-Dunn M (1995) Differential regulation of oocyte maturation and cumulus expansion in the mouse oocyte-cumulus cell 
complex by site-selective analogs of cyclic adenosine monophosphate Developmental Biology 172 72-85

Downs SM, Daniel SA and Eppig JJ (1988) Induction of maturation in cumulus cell-enclosed mouse oocytes by follicle-stimulating hormone and epidermal growth factor: evidence for a positive stimulus of somatic cell origin Journal of Experimental Zoology 245 86-96

Downs SM, Humpherson PG, Martin KL and Leese HJ (1996) Glucose utilization during gonadotrophin-induced meiotic maturation in cumulus cell-enclosed mouse oocytes Molecular Reproduction and Development 44 121-131

Ekholm C and Magnusson C (1979) Rat oocyte maturation: effects of protein synthesis inhibitors Biology of Reproduction 21 1287-1293

Eppig JJ (1989) The participation of cyclic adenosine monophosphate (CAMP) in the regulation of meiotic maturation of oocytes in the laboratory mouse Journal of Reproduction and Fertility Supplement 38 3-8

Eppig JJ and Downs SM (1988) Gonadotrophin-induced murine oocyte maturation in vivo is not associated with decreased cyclic adenosine monophosphate in the oocyte-cumulus cell complex Gamete Research $20125-131$

Eppig J, Freter RR, Ward-Bailey PF and Schultz RM (1983) Inhibition of oocyte maturation in the mouse: participation of cAMP, steroid hormones, and a putative maturation-inhibitory factor Developmental Biology 100 39-49

Eppig JJ, Wigglesworth K, Pendola F and Hirao Y (1997) Murine oocytes suppress expression of luteinizing hormone receptor messenger ribonucleic acid by granulosa cells Biology of Reproduction 56 976-984

Eppig JJ, Pendola FL and Wigglesworth K (1998) Mouse oocytes suppress cAMP-induced expression of LH receptor mRNA by granulosa cells in vitro. Molecular Reproduction and Development 49 327-332

Fagbohun CF and Downs SM (1991) Metabolic coupling and ligandstimulated meiotic maturation in the mouse oocyte-cumulus cell complex Biology of Reproduction 45 851-859

Farin CE and Yang L (1994) Inhibition of germinal vesicle breakdown in bovine oocytes by 5,6-dichloro-1- $\beta$-D-ribofuranosylbenzimidazole (DRB) Molecular Reproduction and Development 37 284-292

Fulka J, Jr, Motlik J, Fulka J and Jilek F (1986) Effect of cycloheximide on nuclear maturation of pig and mouse oocytes (published erratum appears in Journal of Reproduction and Fertility 198678 (1)) Journal of Reproduction and Fertility 77 281-285

Hunter AG and Moor RM (1987) Stage-dependent effects of inhibiting ribonucleic acids and protein synthesis on meiotic maturation of bovine oocytes in vitro. Journal of Dairy Science 70 1646-1651

Hunzicker-Dunn M and Jungmann RA (1978) Rabbit ovarian protein kinases III. Gonadotropin-induced activation of soluble adenosine $3^{\prime}: 5^{\prime}$ monophosphate-dependent protein kinases Endocrinology 103 441-451

Kastrop PM, Hulshof SC, Bevers MM, Destree OH and Kruip TA (1991) The effects of $\alpha$-amanitin and cycloheximide on nuclear progression, protein synthesis, and phosphorylation during bovine oocyte maturation in vitro. Molecular Reproduction and Development 28 249-254

Kidder GM, Green AF and McLachlin JR (1985) On the use of $\alpha$-amanitin as a transcriptional blocking agent in mouse embryos: a cautionary note Journal of Experimental Zoology 233 155-159

Meinecke B and Meinecke-Tillmann S (1993) Effects of $\alpha$-amanitin on nuclear maturation of porcine oocytes in vitro. Journal of Reproduction and Fertility 98 195-201

Ogreid D, Ekanger R, Suva RH, Miller JP and Doskeland SO (1989) Comparison of the two classes of binding sites (A and B) of type I and type II cyclic-AMP-dependent protein kinases by using cyclic nucleotide analogs European Journal of Biochemistry 181 19-31

Osborn JC and Moor RM (1983) Time-dependent effects of $\alpha$-amanitin on nuclear maturation and protein synthesis in mammalian oocytes Journal of Embryology and Experimental Morphology 73 317-338

Peng XR, Hsueh AJ, LaPolt PS, Bjersing L and Ny T (1991) Localization of luteinizing hormone receptor messenger ribonucleic acid expression in ovarian cell types during follicle development and ovulation Endocrinology 129 3200-3207

Pincus G and Enzmann EV (1935) The comparative behaviour of mammalian eggs in vivo and in vitro. Cell Biology $1093347-3354$

Potter RL and Taylor SS (1980) The structural domains of cAMP-dependent protein kinase. I. Characterization of two sites of proteolytic cleavage and homologies to CAMP-dependent protein kinase II Journal of Biological Chemistry 255 9706-9712

SAS (1988) SAS Users' Guide: Statistics Release 6.03 ed. Statistical Analysis Systems Institute Inc., Cary, NC

Schultz RM, Montgomery RR and Belanoff JR (1983a) Regulation of mouse oocyte meiotic maturation: implication of a decrease in oocyte cAMP and protein dephosphorylation in commitment to resume meiosis Developmental Biology 97 264-273

Schultz RM, Montgomery RR, Ward-Bailey PF and Eppig JJ (1983b) Regulation of oocyte maturation in the mouse: possible roles of intercellular communication, CAMP, and testosterone Developmental Biology 95 294-304

Tsafriri A, Lieberman ME, Koch Y, Bauminger S, Chobsieng P, Zor U and Lindner HR (1976) Capacity of immunologically purified FSH to stimulate cyclic AMP accumulation and steroidogenesis in Graafian follicles and to induce ovum maturation and ovulation in the rat Endocrinology 98 655-661

Wolf CJ and Farin CE (1996) Effect of gonadotrophins on the ability of 5,6dichloro-1- $\beta$-D-ribofuranosylbenzamidazole (DRB) to inhibit germinal vesicle breakdown in bovine oocytes Theriogenology $\mathbf{4 6}$ 760-768

Zandomeni R, Bunick D, Ackerman S, Mittleman B and Weinmann R (1983) Mechanism of action of DRB. III. Effect on specific in vitro initiation of transcription Journal of Molecular Biology 167 561-574

Zubay G (1983) Biochemistry pp 820-821. Addison-Wesley Publishing Co., New York

Received 7 November 2001.

First decision 4 January 2002.

Revised manuscript received 11 February 2002.

Accepted 16 March 2002. 